\title{
Rancang Bangun Sistem Informasi Gelanggang Olahraga Berbasis Web dengan Metode Scrum
}

\author{
Dwi Wahyu Adi Nugroho**1, Augie David Manuputty ${ }^{2}$ \\ ${ }^{1,2}$ Universitas Kristen Satya Wacana; Jl. Diponegoro no. 52-60, Salatiga, Kec. Sidorejo, Kota \\ Salatiga, Jawa Tengah 50711, Telp : (0298)321212 \\ ${ }^{3}$ Program Studi Sistem Informasi, FTI UKSW, Salatiga \\ e-mail: *1682017143@student.uksw.edu, ${ }^{2}$ augie.manuputty@uksw.edu
}

\begin{abstract}
Abstrak
Proses bisnis adalah serangkaian langkah yang saling terkait yang ditugaskan kepada setiap pemangku kepentingan untuk pekerjaan tertentu untuk memberikan produk atau layanan kepada pelanggan. Salah satu proses bisnis di Dinas Pemuda dan Olahraga (DISPORA) Salatiga adalah kegiatan peminjaman gedung. Selama ini proses peminjaman gedung masih dilakukan secara manual sehingga menimbulkan kendala dalam penjadwalan pinjaman dan pembayaran. Berdasarkan penelitian sebelumnya menunjukkan bahwa penggunaan metode scrum sangat cocok diterapkan dalam pengembangan atau pengembangan sistem informasi karena metode scrum memiliki kelebihan yaitu dalam kecepatan atau waktu yang singkat. Dengan dibuatnya Sistem Informasi Pusat Olahraga (SIGORA) berbasis web dapat membantu mengatasi permasalahan yang ada di DISPORA karena dengan Sistem Informasi ini penjadwalan dapat dilakukan secara otomatis dan pembayaran dapat dilakukan dengan cara transfer sehingga memudahkan karyawan dan pelanggan.
\end{abstract}

Kata kunci-Proses Bisnis, Sistem Informasi, Scrum.

\begin{abstract}
A business process is a series of interrelated steps assigned to each stakeholder for a specific job to deliver a product or service to a customer. One of the business processes at the Office of Youth and Sports (DISPORA) of Salatiga is the activity of borrowing buildings. So far, the process of borrowing buildings is still done manually, causing an obstacle in scheduling loans and in payments. Based on previous research, it shows that the use of the scrum method is very suitable to be applied in the development or development of information systems because the scrum method has advantages, namely in speed or in a short time. With the creation of a web-based Sports Center Information System (SIGORA), it can help overcome the problems that exist in DISPORA because with this Information System, scheduling can be done automatically and payments can be made by transfer making it easier for employees and customers.
\end{abstract}

Keywords-Business Process, Information System, Scrum.

\section{PENDAHULUAN}

Dinas Kepemudaan dan Olahraga (DISPORA) di Jalan LMU Adi Sucipto No. 2 (Gor Pelajar Hati Beriman) Kota Salatiga, Jawa Tengah. DISPORA adalah instansi pemerintah yang memiliki tugas membantu Walikota. Berdasarkan Peraturan Walikota Salatiga Nomor 46 Tahun 2016 mengenai kedudukan, susunan organisasi, tugas dan fungsi serta tata kerja dinas kepemudaan olahraga, mempunyai tugas pokok untuk melaksanakan urusan pemerintahan dan tugas pembantuan di bidang kepemudaan dan olahraga. 
Salah satu tugas DISPORA Kota Salatiga adalah mengelola gedung olahraga yang terdapat pada Kota Salatiga. Dalam pelaksanaannya DISPORA bertanggung jawab mengelola gedung, peminjaman gedung hingga pembuatan laporan. Saat ini DISPORA masih manual dalam mengelola peminjaman gedung olahraga di Kota Salatiga. Terdapat banyak organisasi yang ingin meminjam gedung baik dari pihak instansi atau dinas, klub olahraga dan acara dari pihak luar, sehingga pihak Dinas Kepemudaan dan Olahraga membutuhkan sebuah sistem informasi peminjaman untuk menunjang pelayanan agar terciptanya kemudahan, kenyamanan dan efisiensi. Berdasarkan kebutuhan tersebut maka dibuatlah aplikasi Sistem Informasi Gelanggang Olahraga (SIGORA) berbasis web.

Dalam pembuatan Sistem Informasi Gelanggang Olahraga (SIGORA) dilakukan menggunakan metode agile dengan model scrum. Metode scrum merupakan metode yang populer digunakan saat ini karena dengan menggunakan metode scrum diharapkan dapat menghasilkan produk yang sesuai dengan keinginan dalam pembuatan sistem informasi.

Dalam keseharian ini terdapat beberapa masalah yang dihadapi oleh DISPORA antara lain, Saat ini dalam menjalankan proses bisnis peminjaman gedung masih dilakukan dengan secara manual, oleh karena itu peneliti membuat cara untuk menerapkan metode scrum untuk mengatasi permasalahan yang ada pada, selain itu peneliti juga membuat cara mengimplementasikan peminjaman gedung menjadi sistem informasi gelanggang olahraga berbasis web.

Tujuan dilakukannya penelitian ini adalah untuk menghasilkan sebuah sistem informasi peminjaman gedung atau SIGORA yang menyediakan informasi gedung, jadwal peminjaman, transaksi pembayaran dengan metode transfer dan laporan bulanan secara otomatis, mempermudah dalam menjalankan proses bisnis pada DISPORA sehingga menjadi efisien dan menerapkan metode scrum sebagai langkah untuk mengatasi permasalahan yang ada pada DISPORA.

Selain itu Penelitian ini berfokus untuk menyelesaikan permasalahan dalam peminjaman gedung pada DISPORA menjadi sebuah sistem yang terintegrasi dan Sistem peminjaman gedung pada DISPORA masih belum terkomputerisasi sehingga menyulitkan pegawai dalam membuat laporan peminjaman dan laporan keuangan.

\section{KAJIAN TEORI}

\subsection{Penelitian Terdahulu}

Dalam jurnal terdahulu terdapat beberapa studi kasus yang menggunakan metode scrum dalam rancang bangun sistem informasi salah satunya adalah Manfaat dari sistem yang terkomputerisasi berbasis web adalah pengelolaan data peminjaman, pembagian tugas pegawai menjadi lebih efektif dan efisien karena sudah terorganisir dengan baik, selain itu data barang masuk dan keluar tersimpan dengan baik dan dapat dengan mudah diakses apabila dibutuhkan, juga proses pelaporan menjadi lebih baik karena dapat diakses dan dicetak secara langsung.[1] Selain itu dalam Jurnal judul "Rancang Bangun Aplikasi E-Portofolio Hasil Karya Mahasiswa UNSERA Menggunakan Metode Scrum" membangun sebuah rancangan aplikasi E-portofolio hasil karya yang memiliki fungsi sebagai penampungan informasi hasil karya mahasiswa UNSERA baik mahasiswa aktif, alumni, Unit Kegiatan Mahasiswa (UKM) dan Himpunan Mahasiswa Jurusan (HMJ) dengan metode scrum yang akan diterapkan di kampus Universitas Serang Raya.[2]

Selain itu terdapat sebuah jurnal dengan judul "Implementasi Model Scrum pada Sistem Informasi Seleksi Masuk Mahasiswa Politeknik Pariwisata Palembang" menjelaskan mengenai sebuah implementasi sistem informasi menggunakan metode scrum. Berdasarkan hasil analisa

Nugroho, et., al [Rancang Bangun Sistem Informasi Gelanggang Olahraga Berbasis Web dengan Metode Scrum] 
yang telah dilakukan menghasilkan informasi bahwa proses pengembangan menggunakan metode scrum sangat tepat untuk kebutuhan akan kecepatan atau waktu yang singkat.[3]

Terdapat pula penelitian terdahulu dengan judul "Implementasi Metode Scrum Dalam Rancang Bangun Sistem Informasi Penjualan (Studi Kasus: Penjualan Sparepart Kendaraan)" yang menggunakan metode kualitatif. Dalam penelitiannya menghasilkan kesimpulan bahwa menggunakan metode scrum membuktikan bahwa proyek pengembangan sistem informasi semakin memerlukan fleksibilitas yang tinggi untuk dapat memenuhi kepuasan pelanggan [4].

Berdasarkan penelitian yang terdahulu dapat disimpulkan bahwa penggunaan metode scrum sangat cocok untuk diterapkan dalam pembangunan ataupun pengembangan sistem informasi. Oleh karena itu peneliti memilih menggunakan metode scrum, karena metode scrum memiliki kelebihan yaitu dalam kecepatan atau waktu yang singkat.

\subsection{Dasar Teori}

Sistem informasi adalah kesatuan dari beberapa elemen yang saling berinteraksi dan tersusun secara sistematis dan teratur untuk menciptakan dan membentuk aliran informasi agar pembuatan keputusan dan melakukan suatu kontrol terhadap organisasi atau perusahaan dapat dilakukan dengan baik dan benar.[5]

Website adalah sebuah halaman informasi yang menggunakan jalur internet sehingga dapat diakses dimanapun dan menggunakan berbagai platform selama terkoneksi dengan jaringan internet. Website sendiri terdiri dari beberapa komponen antara lain teks, gambar, suara, animasi sehingga lebih menarik apabila digunakan untuk media informasi.[6]

PHP atau yang disebut dengan Page Hypertext Preprocessor merupakan bahasa pemrograman yang biasa digunakan pada HTML. Bahasa pemrograman ini dirancang untuk dapat bekerja sama dengan database yang ditujukan agar pembuatan dokumen HTML dapat mengakses database dengan mudah. Kode HTML yang telah dibuat akan diterjemahkan oleh browser sehingga tampilan akan menjadi bentuk informasi yang dapat dibaca oleh semua orang.[7] Pada umumnya aplikasi yang dibangun dengan bahasa pemrograman PHP akan memberikan hasil pada web browser, akan tetapi proses keseluruhan akan berjalan pada server.[8]

MySQL merupakan open source yang berfungsi untuk mengolah suatu database, dimana MySQL sangat mendukung database dengan bahasa pemrograman PHP. [1]

\section{METODE PENELITIAN}

\subsection{Metode Pengumpulan Data}

Dalam sebuah penelitian terdapat 2 jenis teknik pengumpulan data yaitu data primer dan sekunder.[9] Penelitian ini menggunakan teknik pengumpulan data primer sebagai sumber datanya, karena data primer merupakan data yang diperoleh menggunakan cara wawancara, observasi, dan angket.[9] Berikut merupakan teknik pengumpulan data peneliti :

1. Studi Pustaka

Dengan teknik studi pustaka peneliti mempelajari dan mengumpulkan teori yang relevan dengan topik yang dibahas untuk memperoleh informasi tertulis yang berhubungan dengan penelitian.

2. Studi Lapangan

Teknik ini dilakukan peneliti dengan cara datang langsung untuk memperoleh data yang diperlukan dalam pengembangan sistem. Peneliti melakukan studi lapangan dengan metode :

a. Observasi Peneliti melakukan pengamatan langsung pada Dinas Kepemudaan dan Olahraga kota Salatiga terkait sistem informasi yang akan dibuat. 
b. Wawancara Peneliti melakukan komunikasi dua arah dengan pegawai Dinas Kepemudaan dan Olahraga kota Salatiga untuk mendapatkan informasi dan masukan untuk penelitian ini.

Berdasarkan metode pengumpulan data yang digunakan peneliti akan menggunakan metode case studi research. Hasil dari penelitian ini akan menggunakan penulisan jurnal dengan jenis penelitian deskriptif yang menggunakan pendekatan kualitatif. Penelitian dengan menggunakan metode deskriptif merupakan sebuah metode untuk mempelajari kelompok manusia, suatu keadaan, sesuatu tentang pemikiran dan suatu kejadian pada masa kini. Penelitian deskriptif memiliki tujuan untuk membuat deskripsi atau gambaran secara sistematis. Sedangkan pendekatan kualitatif merupakan suatu pendekatan dalam penelitian dengan menggunakan data kalimat tertulis yang memperhatikan konteks studi pada pemahaman, pemikiran persepsi penelitian.

\subsection{Metode Pengembangan Perangkat Lunak}

Metode penelitian merupakan suatu tahap untuk melakukan proses penelitian agar tercapainya hasil yang diharapkan. Pada penelitian ini penulis akan mengimplementasikan metode Agile Scrum untuk membuat Aplikasi SIGORA (Sistem Informasi Gelanggang Olahraga) berbasis web. Metode Agile sering menggunakan model spiral, yang merupakan serangkaian revisi atau iterasi. Berikut merupakan tahap - tahap dalam mengembangkan aplikasi menggunakan metode Agile Scrum yang dijelaskan pada gambar 1:

\section{The Agile - Scrum Framework}

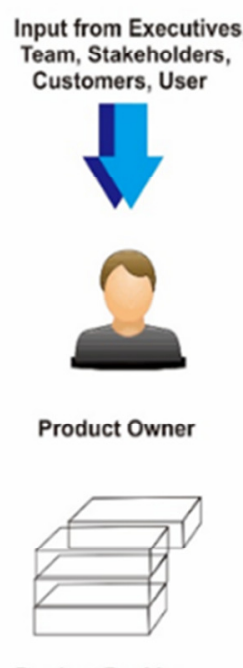

Product Backlog

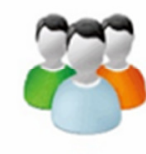

Team

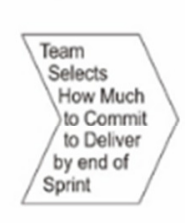

Sprint Planning Meeting

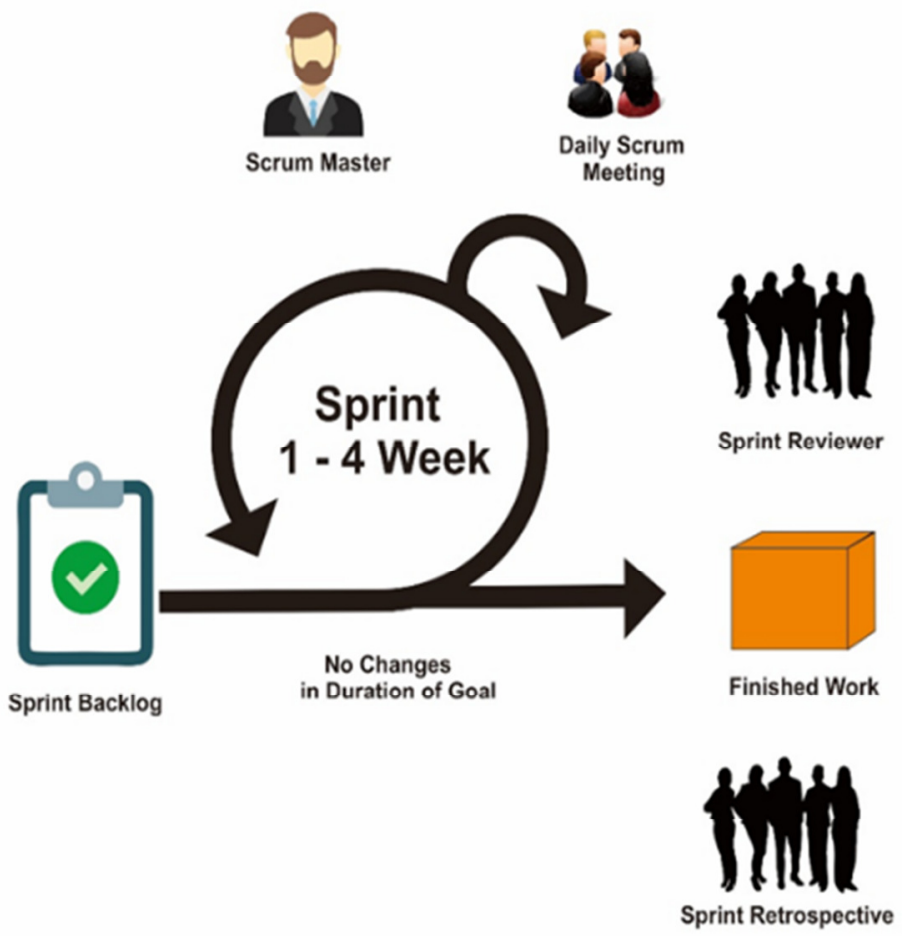

Gambar 1. Framework Agile Scrum 


\section{Product Backlog}

Pada tahap product backlog dilakukan pengelompokan kebutuhan client dan mengetahui tujuan pembuatan sistem. Selain itu juga menjelaskan mengenai kendala atau permasalah yang dihadapi perusahaan atau instansi saat ini. Oleh karena itu, dilakukan proses wawancara mengenai masalah yang sedang dihadapi pada Dinas Kepemudaan dan Olahraga kota Salatiga. Dalam proses wawancara dilakukan dengan bagian IT, bagian keuangan, dan bagian pengelola peminjaman.

\section{Sprint Backlog}

Pada tahapan ini dilakukan pengerjaan sesuai dengan product backlog yang sudah dilakukan analisa kebutuhan. Setelah dilakukan analisa kebutuhan maka produk yang akan dibuat (SIGORA) harus mampu melakukan beberapa hal antara lain : (1) pengguna dapat mengakses website SIGORA di berbagai platform, (2) pengguna dapat melakukan pendaftaran akun pada website SIGORA, (3) dapat melihat data gedung beserta fasilitas yang tersedia, (4) dapat melakukan pemesanan gedung secara otomatis dan real time, dapat melakukan pembayaran non-tunai

3. Sprint

Pada tahap ini team memberikan hasil analisa dan pengerjaan kepada Dinas Kepemudaan dan Olahraga kota Salatiga terkait dengan gambaran bagaimana SIGORA akan dibuat. Selain itu team memaparkan kebutuhan akan jaringan internet, server dan SDM yang akan mengelola SIGORA dan hal-hal mengenai Sistem Informasi Gelanggang Olahraga (SIGORA).

\section{Daily Scrum}

Daily scrum merupakan aktivitas harian dalam proses sprint yang dilakukan untuk memeriksa produk yang sedang dibuat dan apa yang menjadi hambatan dalam pembuatan produk. Daily scrum dinilai sangat memudahkan dan efisien karena pada tiap harinya dilakukan pengecekan dan perbaikan.

\section{HASIL DAN PEMBAHASAN}

\subsection{Product Backlog}

Product backlog merupakan hal dasar yang pertama dijalankan dalam membuat sistem dengan metode Agile Scrum. Pada tahapan ini akan menghasilkan beberapa hal seperti pengguna (user), aktivitas yang dilakukan dan struktur sistem.

1. Analisis Masalah

Pada Dinas Kepemudaan dan Olahraga kota Salatiga terjadi sebuah kendala dalam peminjaman gedung olahraga yang masih dilakukan secara manual, sehingga terjadi kesalahan dalam penjadwalan, dalam pembayaran juga terjadi kendala yaitu terlambat dalam pembayaran.

Dalam tahapan product backlog terdapat beberapa fitur yang diprioritaskan dalam pengembangan sistem informasi gelanggang olahraga, antara lain:

a. Peminjaman Gedung

Dalam peminjaman gedung terdapat foto gedung, kapasitas, fasilitas dan juga deskripsi mengenai gedung tersebut. Berdasarkan SK Walikota Salatiga Nomor 4 tahun 2015 tentang Peminjaman tarif retribusi tempat rekreasi dan olahraga yang dikelola Dinas Pendidikan, Pemuda dan Olahraga terdapat perbedaan tarif berdasarkan kriteria peminjaman yaitu kegiatan skala regional oleh non Pemerintah, kegiatan skala nasional/internasional, kegiatan oleh Cabang Olahraga/Satuan Pendidikan dan kegiatan skala regional oleh Pemerintah. 
b. Pengelolaan jadwal

Dalam pengelolaan jadwal anggota (user) dapat memilih jadwal peminjaman yang diinginkan, jadwal bisa berupa harian, jam dan juga dapat melakukan peminjaman berulang secara otomatis.

c. Pembayaran

Pembayaran dalam SIGORA dapat dilakukan melalui beberapa cara yaitu, DANA, GO-PAY dan transfer. Oleh karena itu DISPORA membutuhkan sebuah Aplikasi berbasis web agar pelayanan terhadap peminjaman gedung menjadi lebih mudah dan efisien, terindeks dengan database, dan memudahkan dalam pengelolaan aset. Hal ini diprioritaskan karena saat ini peminjaman aset DISPORA masih belum terkomputerisasi dan laporan keuangan dibuat masih menggunakan aplikasi yang sederhana sehingga menyulitkan pegawai.

\subsection{Analisis Kebutuhan Fungsional}

Dalam pembuatan aplikasi SIGORA terdapat 5 jenis user untuk aplikasi, antara lain:

1. Anggota

2. Admin SIGORA

3. Kepala Dinas

4. Bagian Pengelola

5. Bagian Keuangan

Tabel 1. Aktivitas User

\begin{tabular}{|c|c|c|}
\hline $\begin{array}{l}\text { Kategori } \\
\text { Pengguna }\end{array}$ & Fasilitas & Hak Akses \\
\hline Admin SIGORA & $\begin{array}{l}\text { - Mengelola data anggota } \\
\text { - Mencari data Peminjaman } \\
\text { berdasarkan ID Anggota } \\
\text { - Mengelola Data Gedung }\end{array}$ & $\begin{array}{l}\text { - Akses ke menu Kelola Data } \\
\text { Anggota } \\
\text { - Akses ke menu Data Peminjaman }\end{array}$ \\
\hline Kepala Dinas & $\begin{array}{l}\text { - Melihat semua laporan } \\
\text { keuangan }\end{array}$ & - Akses ke menu Laporan Keuangan \\
\hline $\begin{array}{l}\text { Bagian } \\
\text { Keuangan }\end{array}$ & $\begin{array}{l}\text { - Mengelola laporan } \\
\text { keuangan }\end{array}$ & $\begin{array}{l}\text { - Akses ke menu Laporan Keuangan } \\
\text { - Mencetak laporan keuangan }\end{array}$ \\
\hline $\begin{array}{l}\text { Bagaian } \\
\text { Pengelola }\end{array}$ & $\begin{array}{l}\text { - Melakukan pengecekan } \\
\text { fasilitas gedung } \\
\text { - Melakukan pengelolaan } \\
\text { terhadap peminjaman }\end{array}$ & $\begin{array}{l}\text { - Akses ke menu Edit Data Gedung } \\
\text { - Akses ke menu Peminjaman }\end{array}$ \\
\hline Anggota & $\begin{array}{l}\text { - Melakukan peminjaman } \\
\text { - Melihat data gedung } \\
\text { - Melakukan edit profil } \\
\text { - Melakukan pembayaran }\end{array}$ & $\begin{array}{l}\text { - Akses ke Halaman Utama Website } \\
\text { SIGORA } \\
\text { - Akses ke data gedung } \\
\text { - Akses ke riwayat transaksi }\end{array}$ \\
\hline
\end{tabular}

Berdasarkan analisa pada tabel 1 dapat dilakukan identifikasi mengenai skala prioritas kebutuhan sistem yang akan dikembangkan. 
Tabel 2. Product Backlog

\begin{tabular}{|c|l|c|}
\hline No & \multicolumn{1}{|c|}{ Item } & $\begin{array}{c}\text { Skala } \\
\text { Prioritas }\end{array}$ \\
\hline 1 & Halaman Login & Tinggi \\
\hline 2 & Dashboard & Rendah \\
\hline 3 & Form Peminjaman Gedung & Tinggi \\
\hline 4 & Menu Detail Gedung & Sedang \\
\hline 5 & Menu Pembayaran & Tinggi \\
\hline 6 & Menu Jadwal Peminjaman & Tinggi \\
\hline 7 & Tata Cara Peminjaman & Tinggi \\
\hline
\end{tabular}

\subsection{Perancangan Use Case Diagram}

Use Case Diagram digunakan sebagai langkah untuk mengidentifikasi aktor dalam suatu sistem informasi gelanggang olahraga berbasis web serta menggambarkan hal apa saja yang dapat dilakukan oleh masing-masing aktor dalam sistem. Berdasarkan analisa pada tabel 1 dapat digambarkan use case diagram sebagai berikut. Penggunaan use case memberikan kelebihan pada developer dapat melakukan analisa fungsional, menggambarkan lingkup sistem menjadi bagian yang mudah dimengerti dan dikelola, menyajikan spesifikasi fungsional yang digunakan untuk melakukan desain UI dan UX [10].

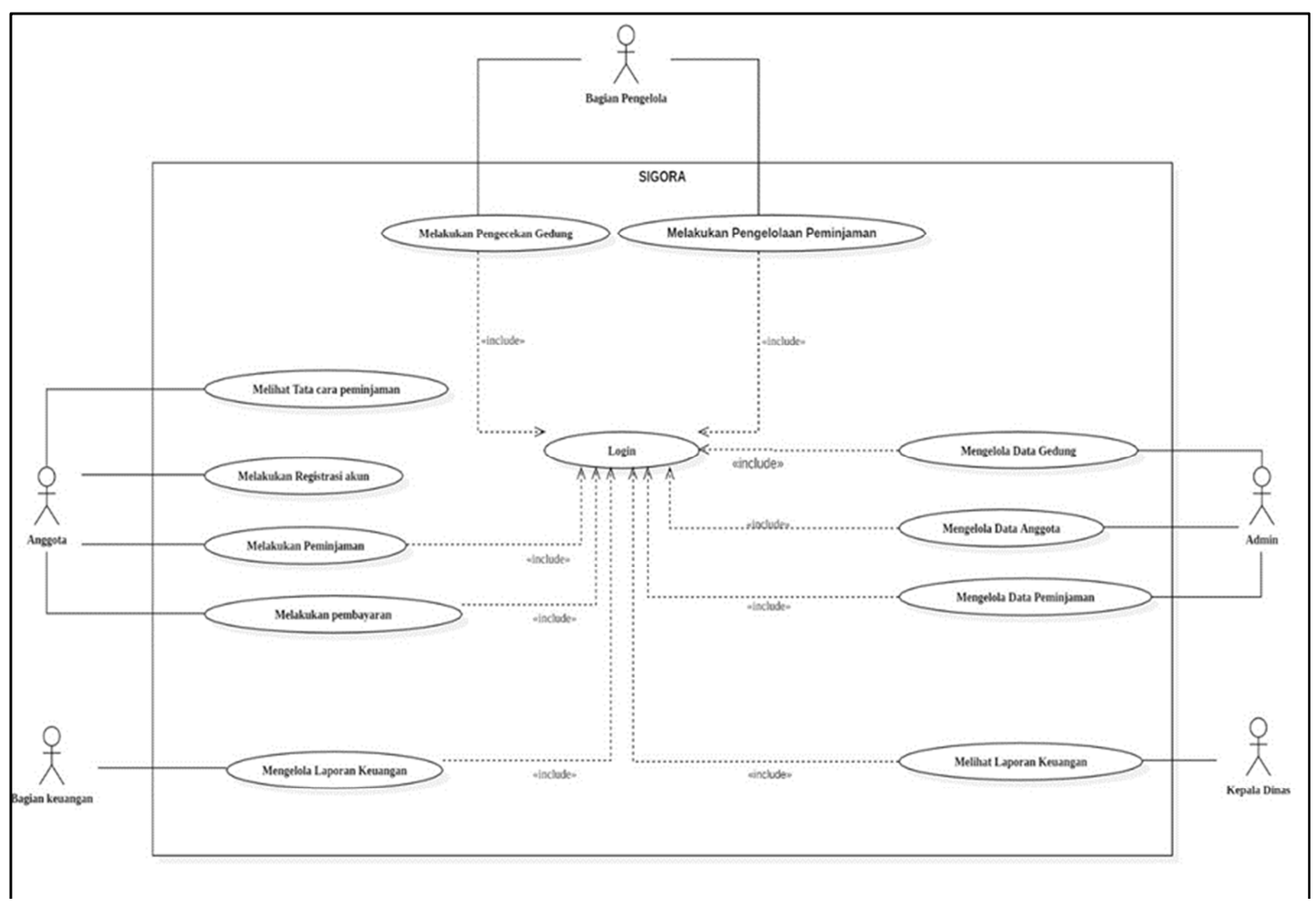

Gambar 2. Use Case Diagram

\subsection{Flowchart Diagram}

Flowchart diagram merupakan gambaran alur dari sebuah sistem berjalan dari awal hingga akhir. Untuk menggambarkan proses sistem SIGORA, gambar 3 merupakan flowchart diagram SIGORA. 


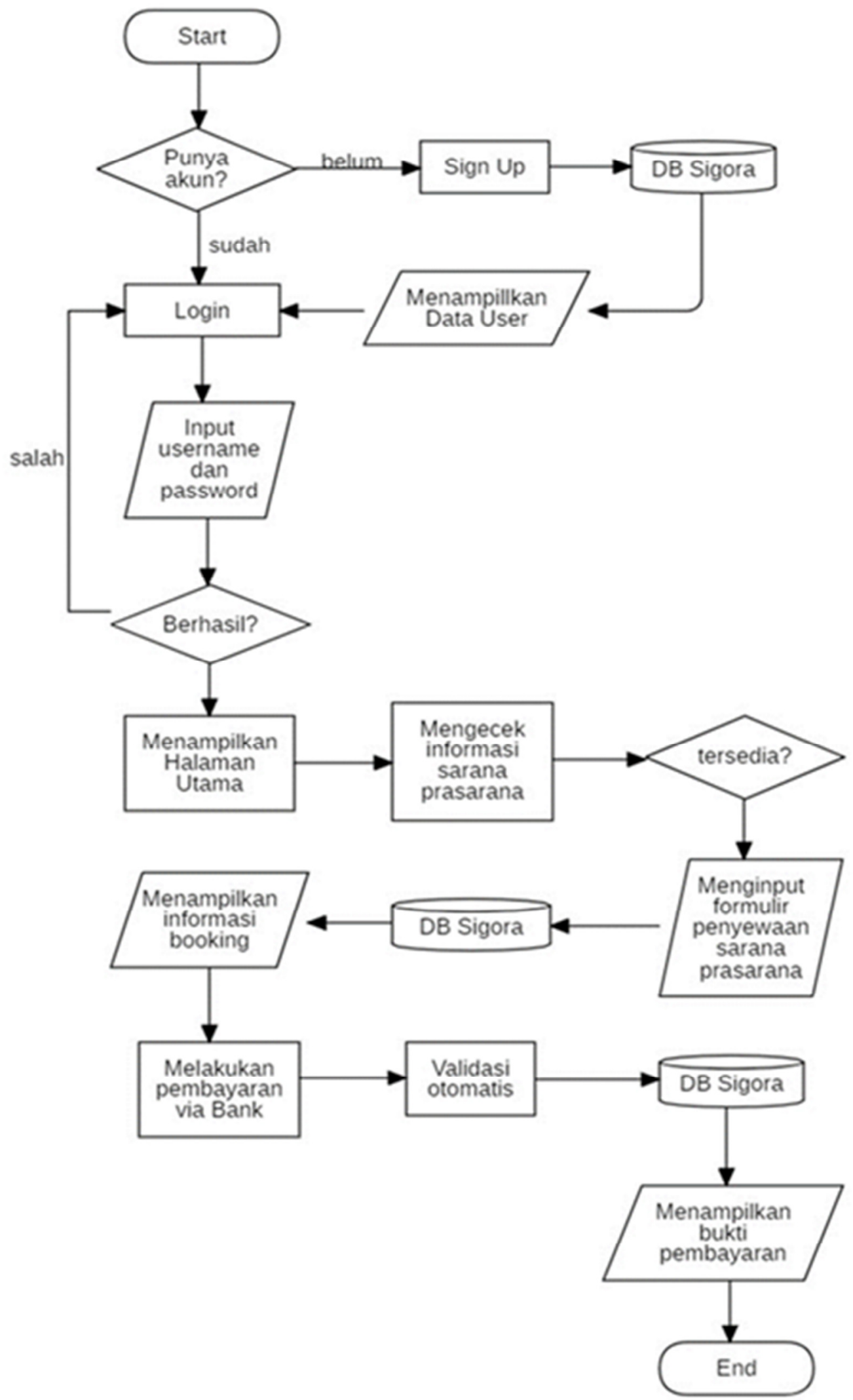

Gambar 3. Flowchart Diagram

Nugroho, et., al [Rancang Bangun Sistem Informasi Gelanggang Olahraga Berbasis Web dengan Metode Scrum] 


\subsection{Perancangan Struktur Menu}

Dalam gambar 4 perancangan struktur menu sistem didesain untuk gambaran visual tentang urutan menu sistem yang dapat diakses oleh $u$ ser.

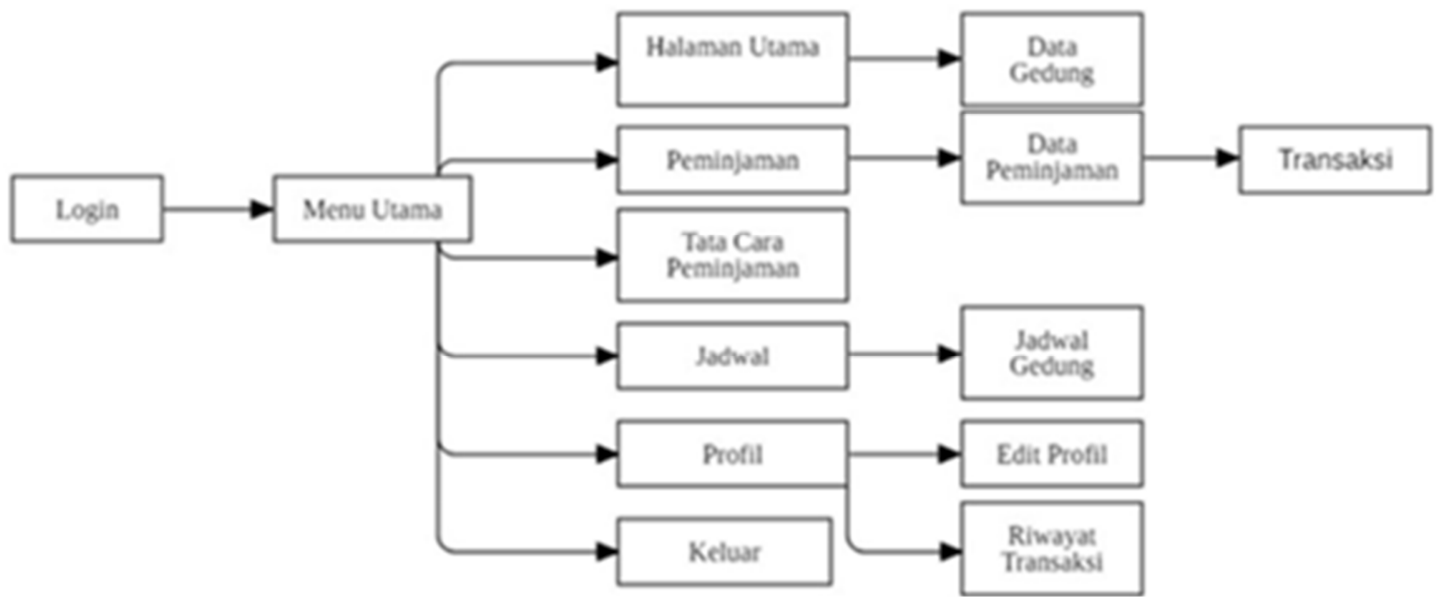

Gambar 4. Perancangan Struktur Menu

\subsection{Sprint Backlog}

Dalam tahapan ini website sigora diharapkan mampu berjalan di berbagai platform antara lain android, windows dan juga mac. Oleh karena itu diperlukan pembagain waktu dan tahap pembuatan dalam rancang bangun SIGORA, berikut adalah tabel 3 sprint backlog.

Tabel 3. Sprint Backlog

\begin{tabular}{|l|l|c|c|c|c|c|c|c|}
\hline Sprint & \multicolumn{1}{|c|}{ Task } & \multicolumn{6}{|c|}{ Estimasi Waktu } \\
\hline \multirow{4}{*}{$\begin{array}{c}\text { Pengelolaan } \\
\text { Gedung }\end{array}$} & Membuat Database & 1 & 2 & 3 & 4 & 5 & 6 & 7 \\
\cline { 2 - 8 } & $\begin{array}{l}\text { Membuat tampilan } \\
\text { front-end }\end{array}$ & 3 & 2 & & & & & \\
\cline { 2 - 8 } & Melakukan Coding & 4 & 3 & & & & & \\
& Melakukan Testing & & 5 & 5 & 4 & & & \\
\cline { 2 - 8 } & Total & \multicolumn{6}{|c|}{ 24 Jam } \\
\hline
\end{tabular}

\subsection{Sprint}

Pada tahapan sprint merupakan tahapan dimana peneliti melakukan proses pembuatan produk berdasarkan tabel sprint backlog. Setelah use case diagram selesai dibuat, maka langkah selanjutnya adalah membuat flowchart diagram dimana diagram ini berfungsi sebagai gambaran alur dalam sistem.

Langkah selanjutnya adalah membuat activity diagram, dimana diagram ini berfungsi sebagai gambaran apa yang dilakukan user dalam suatu proses yang berlangsung. Gambar 5 merupakan activity diagram proses peminjaman gedung pada SIGORA: 


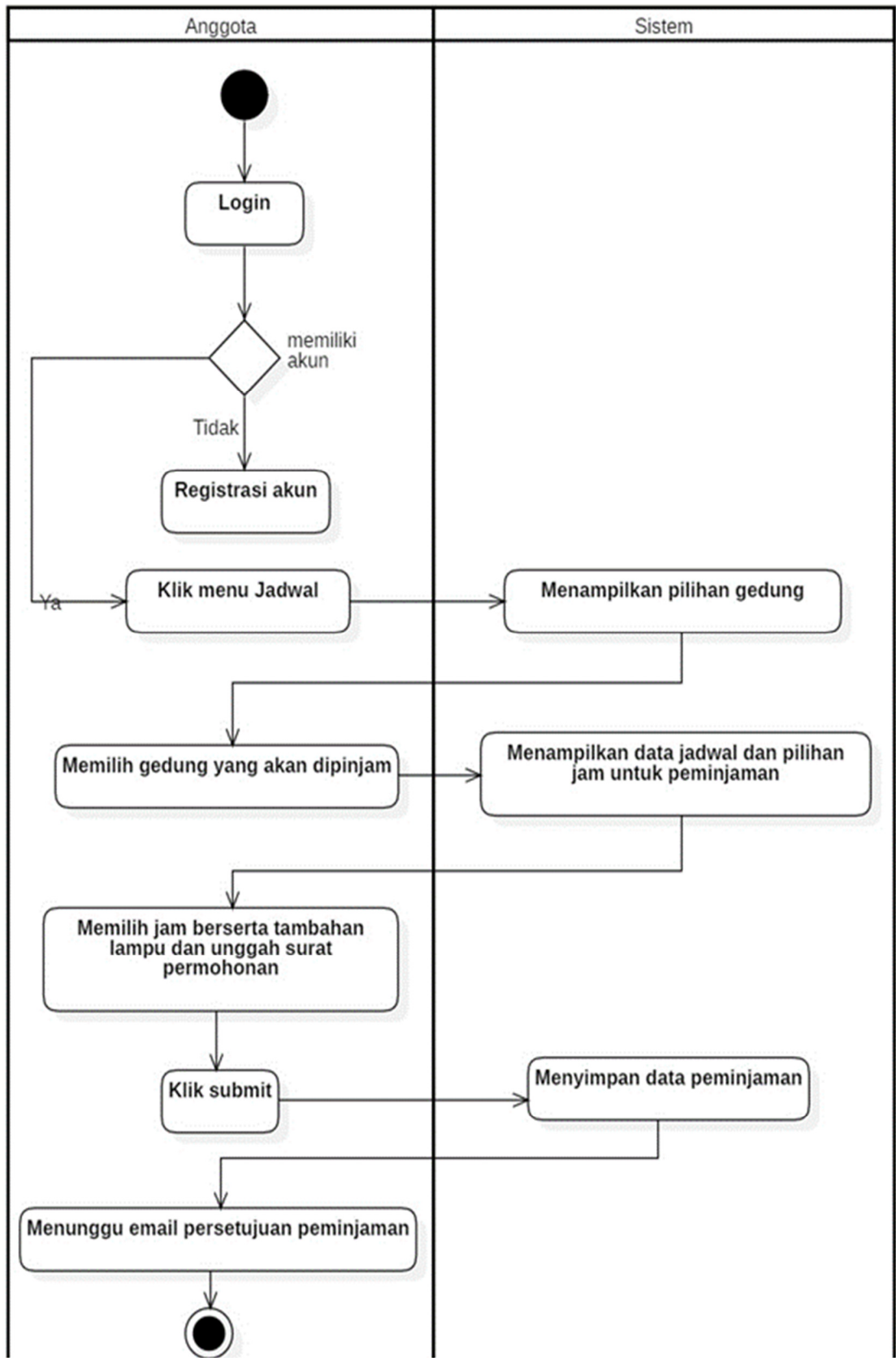

Gambar 5 Activity Diagram Peminjaman Gedung 


\subsection{Daily Scrum}

Dalam pembuatan aplikasi SIGORA tiap harinya akan diadakan sebuah pertemuan rutin yang dilakukan untuk melakukan evaluasi pekerjaan yang dilakukan, hambatan yang dihadapi dan target yang harus diselesaikan pada pertemuan rutin selanjutnya.

\subsection{Sprint Review}

Tahapan selanjutnya setelah serangkaian kegiatan selesai dikerjakan, makan akan menghasilkan sebuah produk aplikasi SIGORA yang akan dilakukan demonstrasi pada tahapan sprint review. Produk aplikasi SIGORA akan dilakukan pemeriksaan bug dan testing secara berkala untuk mengetahui apakah produk yang dibuat sesuai dengan kebutuhan. Berikut merupkan gambaran desain ui tampilan awal dari aplikasi sigora berbasis web.

1. Halaman Login

Gambar 6 merupakan tampilan login page pada SIGORA.

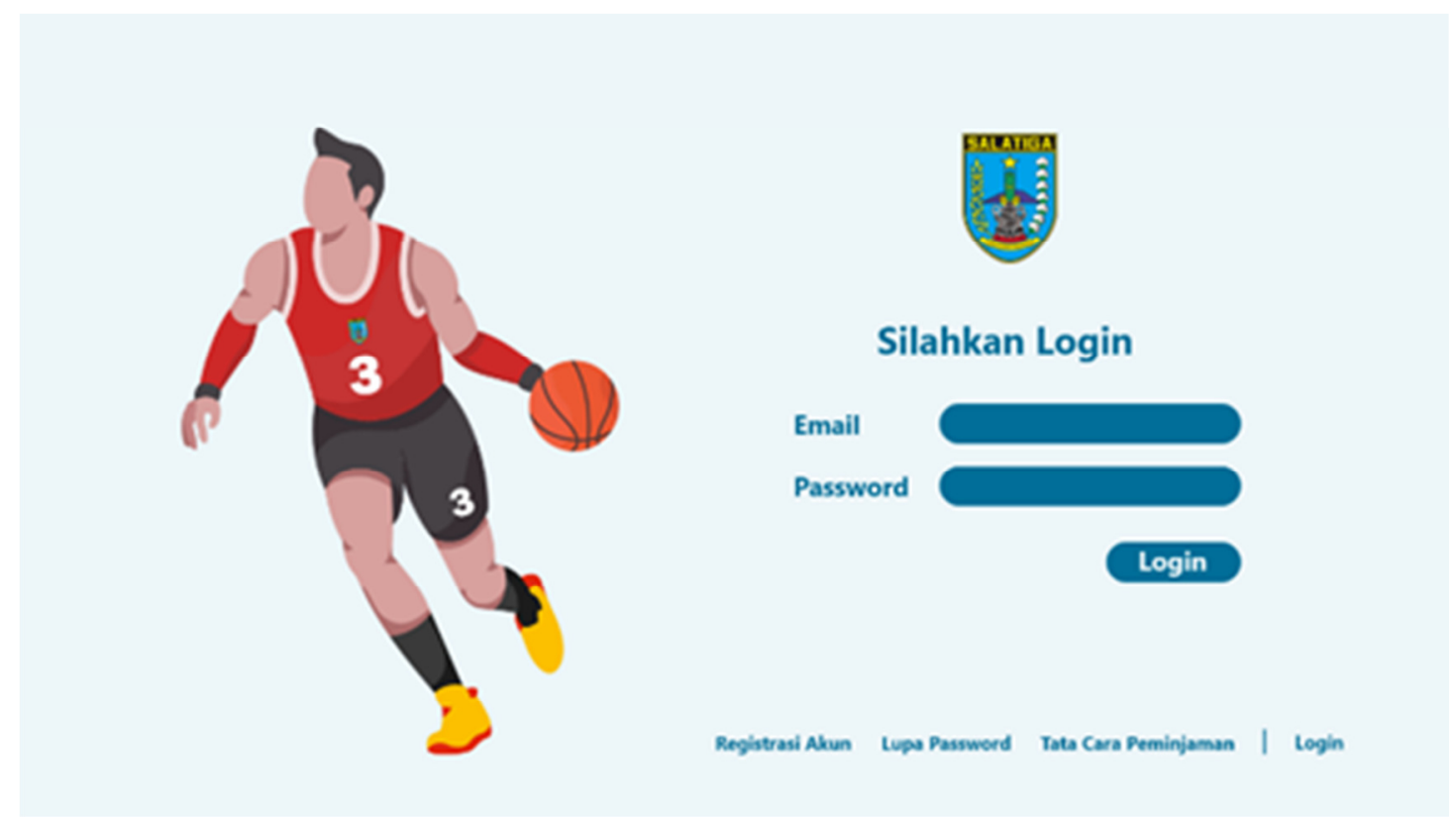

Gambar 6. Tampilan Login Page

2. Halaman Tata Cara Peminjaman

Dibuatnya halaman tata cara peminjaman adalah untuk memberikan informasi kepada pengunjung tentang alur peminjaman yang ada di website SIGORA pada gambar 7. 



Gambar 7. Tampilan Tata Cara Peminjaman

3. Halaman Utama
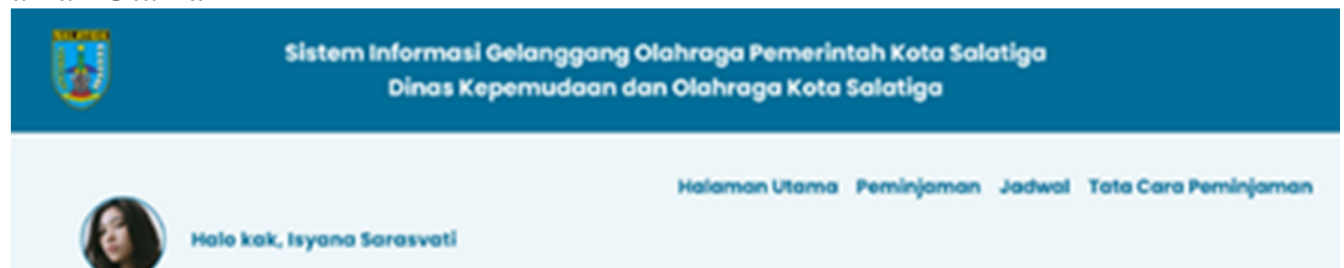

Holo kak, isyono Soroswotl

Holomon Utoma Peminjoman sodwol Toto Caro Pominjamon

\section{SIGORA}

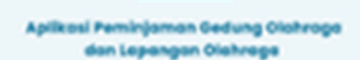

Godung Olahraga Kota Salatiga
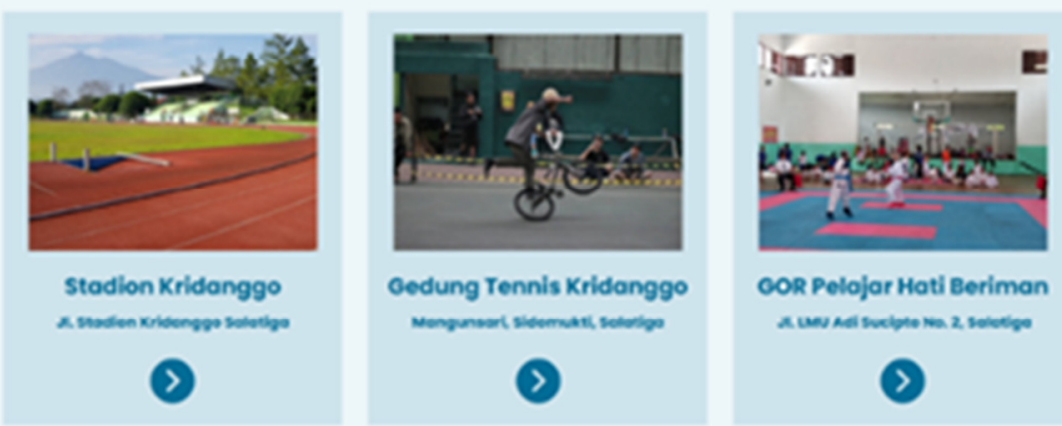

Gambar 8 Tampilan Awal dari SIGORA

Nugroho, et., al [Rancang Bangun Sistem Informasi Gelanggang Olahraga Berbasis Web dengan Metode Scrum] 
Gambar 8 merupakan tampilan dari halaman utama sistem gelanggang olahraga (SIGORA) dan halaman ini merupakan tampilan awal saat user mengakses web.

\section{Halaman data Gedung}

Gambar 9 merupakan tampilan data gedung berisi alamat gedung dan spesifikasi yang dimiliki gedung.

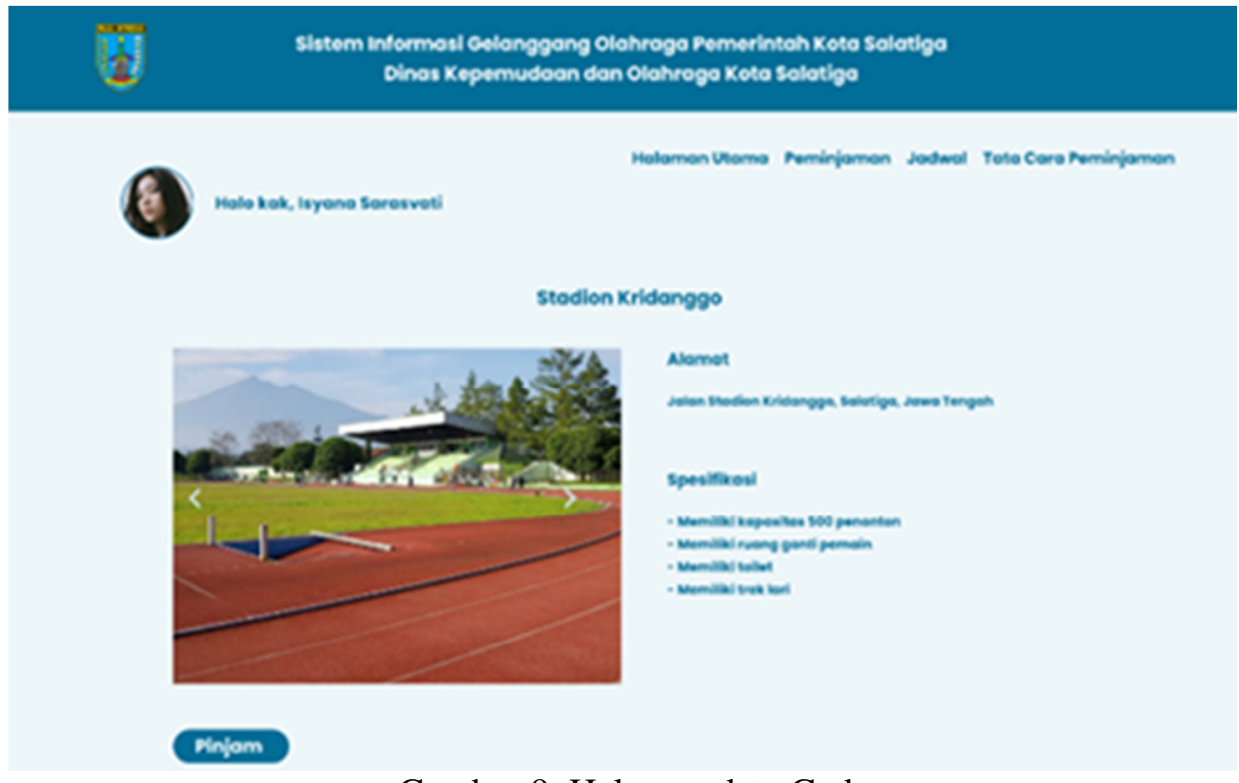

Gambar 9. Halaman data Gedung

\section{Halaman jadwal gedung}

Gambar 10 merupakan tampilan dari jadwal gedung. Disini anggota dapat melakukan peminjaman dengan memilih hari yang tersedia dan memilih kriteria peminjam dan unggah surat permohonan.

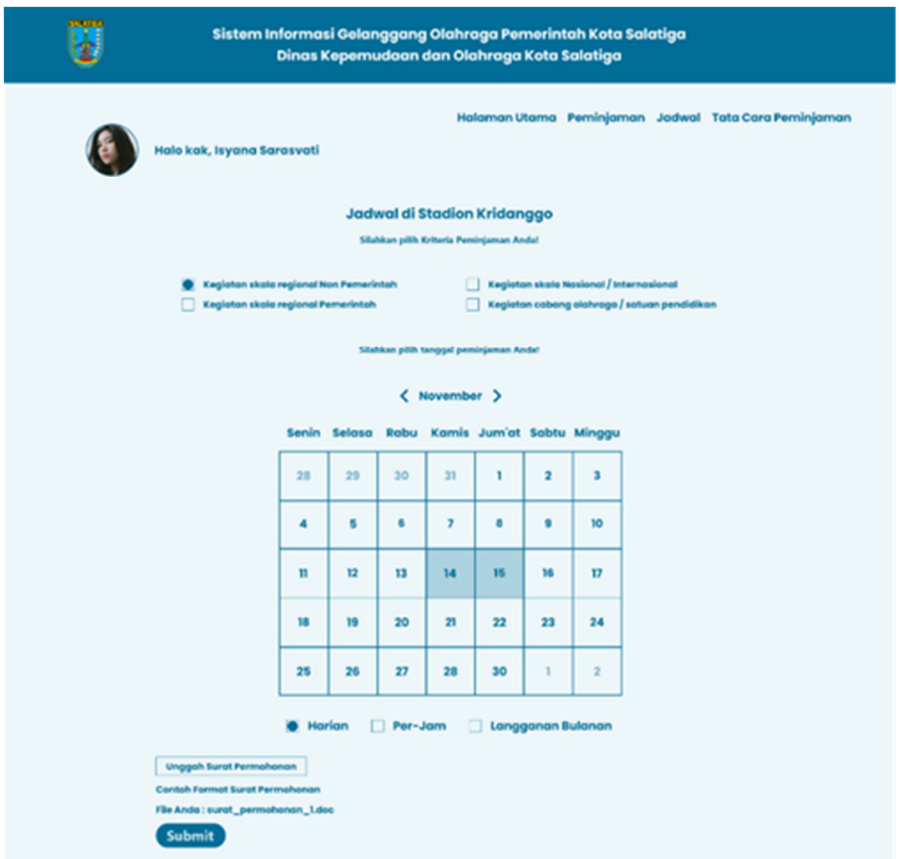

Gambar 10. Halaman Jadwal Gedung

Nugroho, et., al [Rancang Bangun Sistem Informasi Gelanggang Olahraga Berbasis Web dengan Metode Scrum] 
6. Halaman menu peminjaman

Gambar 11 merupakan tampilan peminjaman SIGORA. Terdapat rangkuman peminjaman yang telah dipilih dan total biaya yang harus dibayarkan.
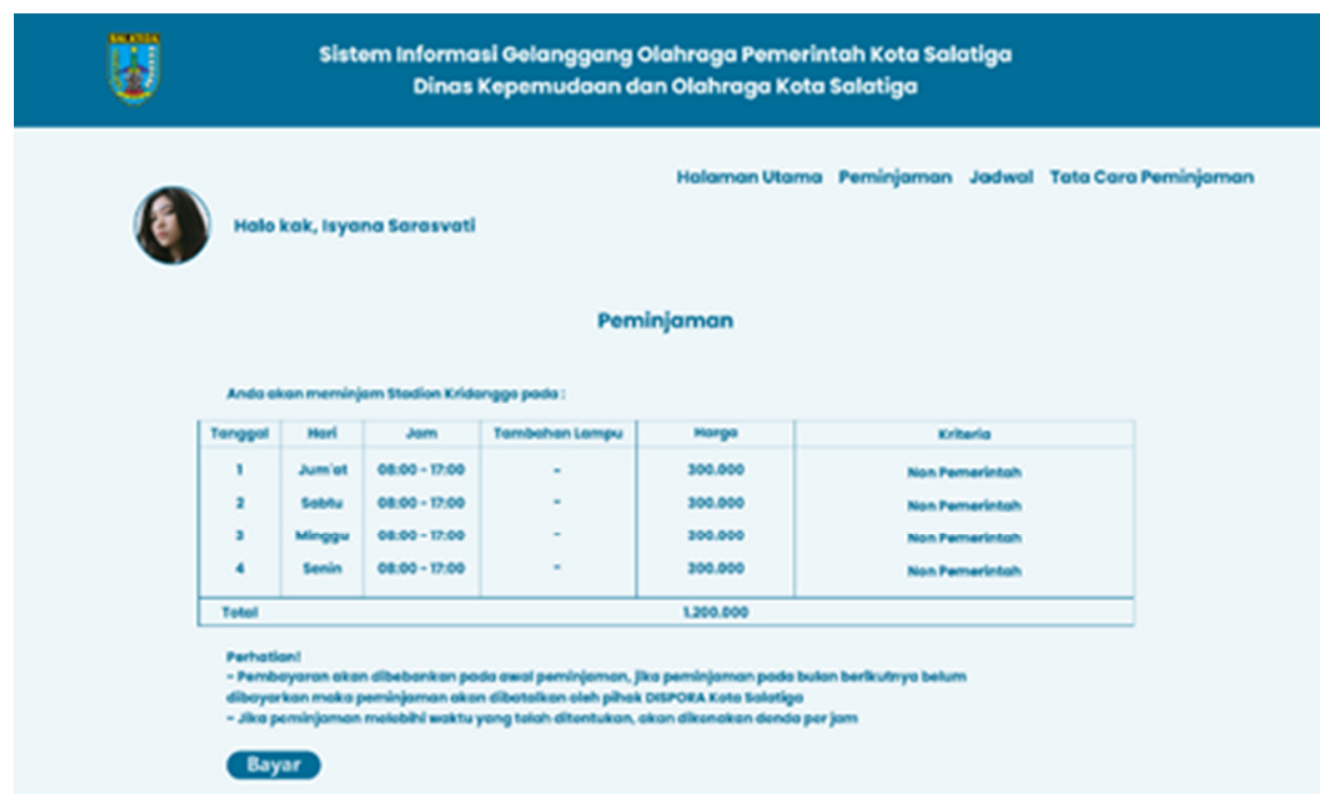

Gambar 11. Halaman Peminjaman

7. Halaman pembayaran

Gambar 12 merupakan tampilan halaman pembayaran. Terdapat pilihan metode pembayaran, detail pembayaran dan petunjuk pembayaran.

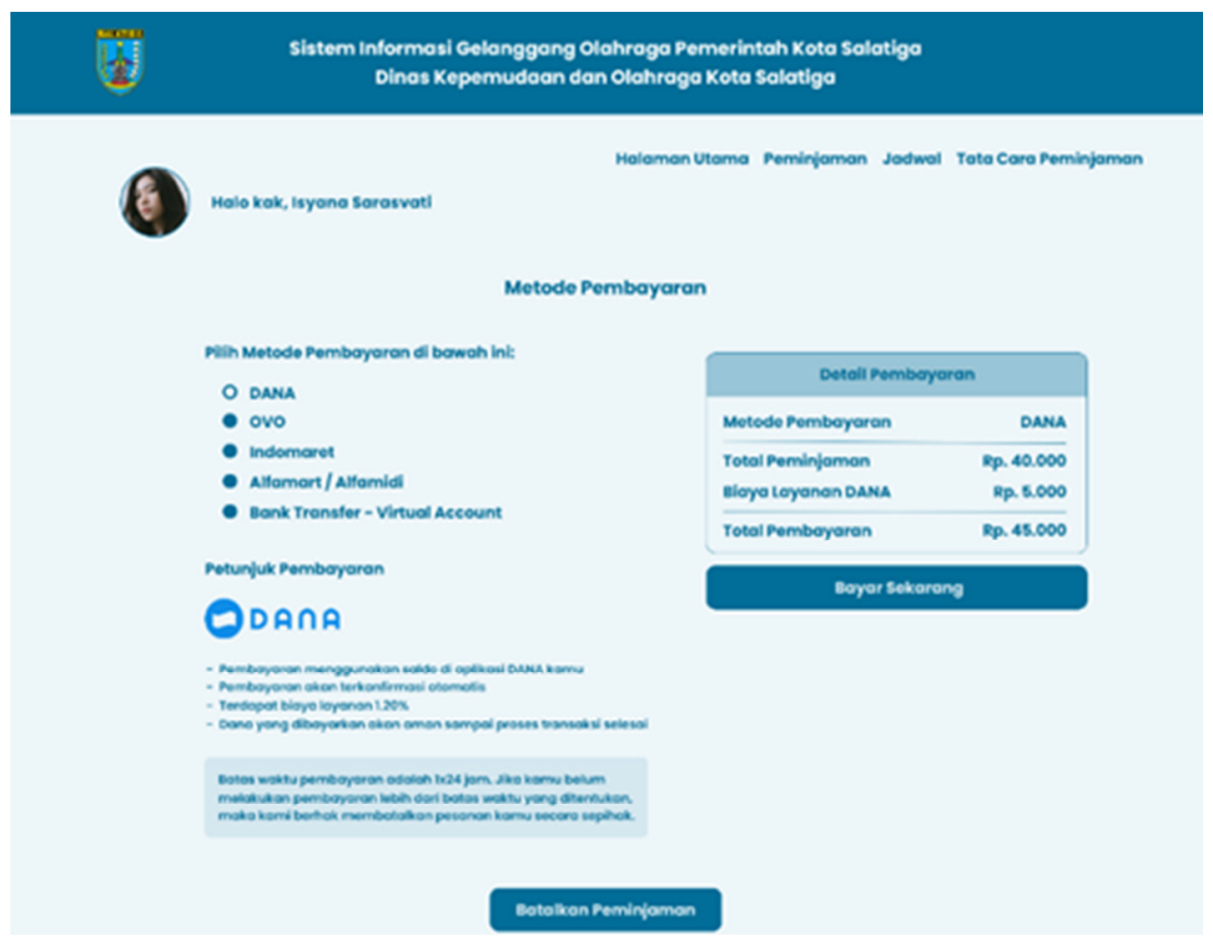

Gambar 12. Halaman Pembayaran

Nugroho, et., al [Rancang Bangun Sistem Informasi Gelanggang Olahraga Berbasis Web dengan Metode Scrum] 


\section{Prototype UI}

Gambar 13 merupakan prototype UI atau simulasi bagaimana anggota berinteraksi atau cara kerja web dengan UI secara nyata.

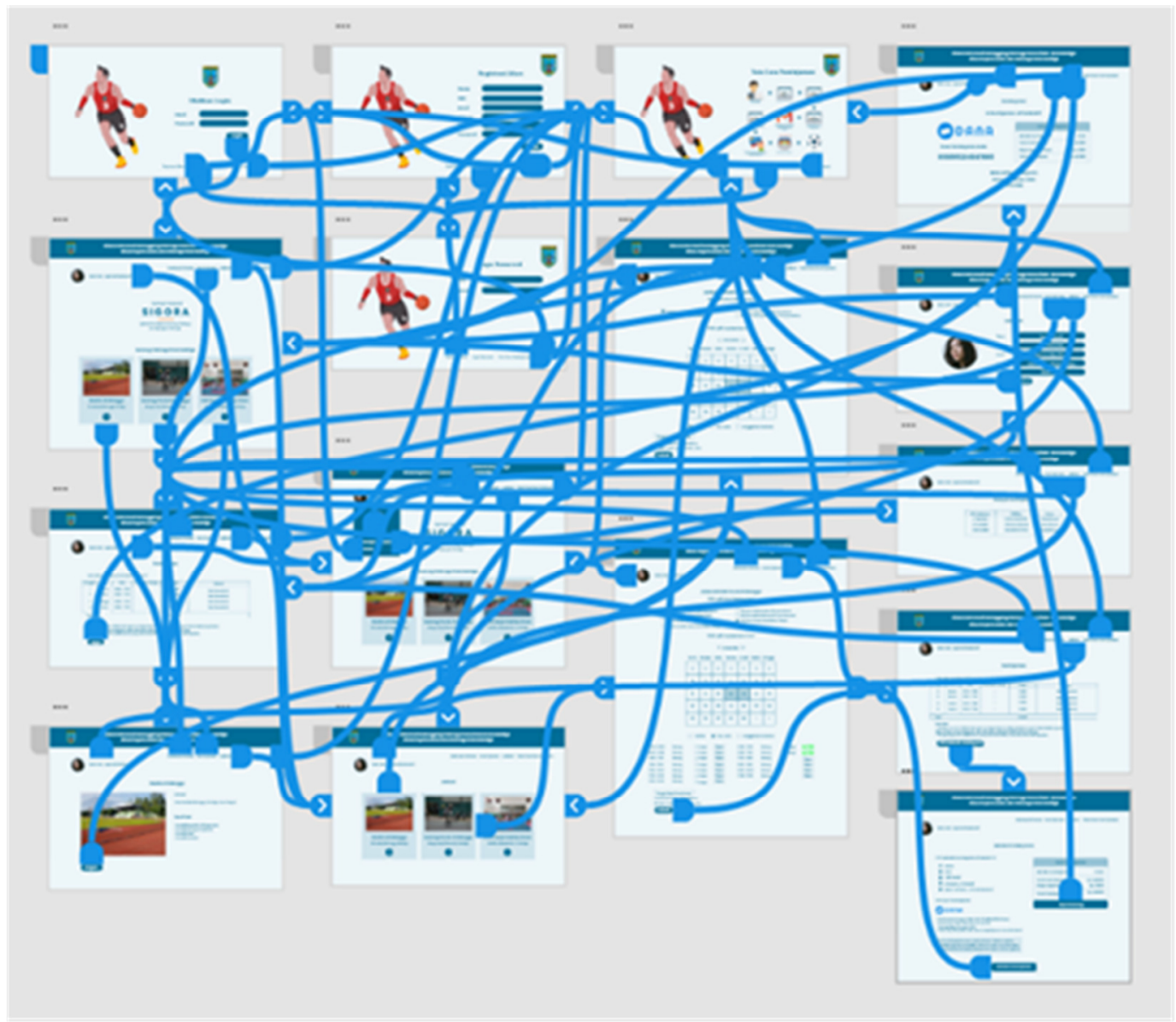

Gambar 13. Prototype UI

\section{KESIMPULAN}

Berdasarkan hasil dari penelitian yang dilakukan, dapat disimpulkan bahwa dalam perancangan Sistem Informasi Gelanggang Olahraga (SIGORA) menggunakan metode agile scrum menjadi lebih optimal dan efektif. Pada tahap analisis desain sistem informasi sangat menentukan bagaimana produk akan dibuat dan dengan analisis tersebut kita dapat melakukan pengembangan lebih lanjut. Dalam pengimplementasian metode agile scrum kita dapat menyelesaikan sebuah produk sistem dengan koordinator antar tim agar tercapai tujuan suatu produk yang selaras. Dengan menggunakan metode tersebut kita juga dapat dengan mudah melakukan controlling dalam pembuatan sistem pada tiap harinya karena selalu akan diadakan meeting secara berkala pada tahapan daily scrum. Selain itu pemilihan pembuatan sistem menggunakan web juga memudahkan user dalam mengakses, hal ini dikarenakan saat ini website sudah dapat diakses dimana saja dan di berbagai platform seperti Android, Windows, Linux, maupun maupun MacOs. 


\section{SARAN}

Untuk peneliti selanjutnya sebaiknya perbanyak trial dan error dalam pembuatan sistem informasi agar dapat mengurangi kesalahan. Selain itu dalam pembuatan sistem informasi sebaiknya dilakukan pemilihan fitur agar tidak terbuang sia sia.

\section{UCAPAN TERIMAKASIH}

Penulis mengucapkan terimakasih kepada Allah SWT yang telah memberikan rahmat dan hidayahnya karena dengan izinnya penulis dapat menyelesaikan pembuatan jurnal sebagai tugas akhir perkuliahan untuk mendapatkan gelar Sarjana, selain itu ucapan terimakasih kepada keluarga tercinta yang selalu memberikan dukungan dari awal perkuliahan hingga saat ini, dan juga kepada Dosen dan seluruh karyawan UKSW yang selalu memberikan layanan yang baik kepada mahasiswa.

\section{DAFTAR PUSTAKA}

[1] A. O. Sari dan E. Nuari, 2017. "Rancang Bangun Sistem Informasi Persediaan Barang Berbasis Web Dengan Metode FAST (Framework For The Applications)," Vol. 13, No. 2, pp. 261-266,

[2] D. Fernando, A. Anharudin, dan F. Fadli, 2018, "Rancang Bangun Aplkasi E-Portofolio Hasil Karya Mahasiswa UNSERA Menggunakan Metode Scrum," JsiI (Jurnal Sist. Informasi), Vol. 5, No. 1, PP. 7-12, DOI: 10.30656/jsii.v5i1.579.

[3] U. Ependi, "Implementasi Model Scrum pada Sistem Informasi Seleksi Masuk Mahasiswa Politeknik Pariwisata Palembang,” J.Inform. J. Pengemb.IT, Vol. 3, No. 1, pp. 49-55, 2018,[Online]. Available: http://ejournal.poltektegal.ac.id/index.php/informatika/article/view/640.

[4] M. N. Novri Hadinata, 2017, "Implementasi Metode Scrum Dalam Rancang Bangun Sistem Informasi Penjualan (Studi Kasus: Penjualan Sparepart Kendaraan)," J.Ilm.Betrik, Vol. 08, No. 01, pp. 22-27, [Online].Available: https://ejournal.lppmstipagaralam.ac.id/index.php/betrik/index.

[5] A. May, P. Studi, dan M. Informatika, 2017. "Perlengkapan Tidur Berbasis Web," Vol. 19, No. 2, pp. 127-130,

[6] Y. A. Ferdiyanto, 2019, "Perancangan Sistem Informasi Pemerintahan Berbasis Web Studi Kasus Kantor Kelurahan Sumur Batu,” Vol. XXI, No. 1, pp. 2017-2020, DOI: 10.31294/p.v20i2.

[7] S. Wahyuni dan N. Cahyani, "Penerapan Model Spiral Dalam Pengembangan Sistem Informasi Penjadwalan Produksi Berbasis Website (Studi Kasus: PT. Dinar Makmur Cikarang)," Informatics Digit. Expert, Vol. 2, No. 1, pp. 1-6, 2020, DOI: 10.36423/IDE.V2i1.425. 
[8] M. Susilo, 2018, "Rancang Bangun Website Toko Online Menggunakan Metode Waterfall," InfoTekJar (Jurnal Nas.Inform.dan Teknol. Jaringan), Vol. 2, No. 2, pp. 98105, DOI : 10.30743/infotekjar.v2i2.171.

[9] K. Puspita, Y. Alkhalifi, dan H. Basri, 2021. "Rancang Bangun Sistem Informasi Penerimaan Peserta Didik Baru Berbasis Website Dengan Metode Spiral,” Vol. 23, No. 1 , pp. 35-42,

[10] W. Warkim, M.H. Muslim, F. Harvianto, dan S.Utama, 2020, "Penerapan Metode SCRUM Dalama Pengembangan Sistem Informasi Layanan Kawasan," J.Tek.Inform.Dan Sist.Inf., Vol. 6, No. 2, pp. 365-378, DOI: 10.28932/jutisi.v6i2.2711. 